\title{
Towards eliminating malaria in high endemic countries: the roles of community health workers and related cadres and their challenges in integrated community case management for malaria: a systematic review
}

\author{
Bruno F. Sunguya ${ }^{1 *}$, Linda B. Mlunde ${ }^{2}$, Rakesh Ayer $^{3}$ and Masamine Jimba ${ }^{3}$
}

\begin{abstract}
Background: Human resource for health crisis has impaired global efforts against malaria in highly endemic countries. To address this, the World Health Organization (WHO) recommended scaling-up of community health workers (CHWs) and related cadres owing to their documented success in malaria and other disease prevention and management. Evidence is inconsistent on the roles and challenges they encounter in malaria interventions. This systematic review aims to summarize evidence on roles and challenges of $\mathrm{CHWs}$ and related cadres in integrated community case management for malaria (iCCM).
\end{abstract}

Methods: This systematic review retrieved evidence from PubMed, CINAHL, ISI Web of Knowledge, and WHO regional databases. Terms extracted from the Boolean phrase used for PubMed were also used in other databases. The review included studies with Randomized Control Trial, Quasi-experimental, Pre-post interventional, Longitudinal and cohort, Cross-sectional, Case study, and Secondary data analysis. Because of heterogeneity, only narrative synthesis was conducted for this review.

Results: A total of 66 articles were eligible for analysis out of 1380 studies retrieved. CHWs and related cadre roles in malaria interventions included: malaria case management, prevention including health surveillance and health promotion specific to malaria. Despite their documented success, CHWs and related cadres succumb to health system challenges. These are poor and unsustainable finance for iCCM, workforce related challenges, lack of and unsustainable supply of medicines and diagnostics, lack of information and research, service delivery and leadership challenges.

Conclusions: Community health workers and related cadres had important preventive, case management and promotive roles in malaria interventions. To enable their effective integration into the health systems, the identified challenges should be addressed. They include: introducing sustainable financing on iCCM programmes, tailoring their training to address the identified gaps, improving sustainable supply chain management of malaria drugs and diagnostics, and addressing regulatory challenges in the local contexts.

Keywords: Community health workers, Malaria, Community case management, Malaria endemicity

\footnotetext{
*Correspondence: sunguya@gmail.com

1 Department of Community Health, School of Public Health and Social

Sciences, Muhimbili University of Health and Allied Sciences, Dar es

Salaam, Tanzania

Full list of author information is available at the end of the article
} 


\section{Background}

Mortality among children under 5 years old has fallen by more than $50 \%$ in the last decade [1]. However, the global burden of diseases and years of life lost are still high in low and middle-income countries owing to infectious diseases, including malaria [1]. Malaria burden remains high despite the knowledge of effective interventions [2]. Such interventions include community-based approaches for prevention and treatment of common illnesses responsible for high mortality and morbidity, such as malaria [3-5].

Community-based interventions call for individuals available in and originated from the respective communities to implement them. Community health workers (CHWs) have been effective in improving access to preventative, promotive and curative interventions in the communities they serve [6]. In malaria interventions, $\mathrm{CHWs}$ and related cadres have improved outcomes in disease control by tailoring interventions to local needs and regulations. The World Health Organization (WHO) has endorsed $\mathrm{CHW}$-led interventions and encouraged its member states to embrace integrated community case management (iCCM) approaches and policies to address child mortality [7].

The iCCM approach using CHWs and related cadres has been effective in managing and preventing child deaths due to malaria in various contexts $[6,8]$. Their use is cost-effective [9]. However, more than half a million children still die of malaria every year [1]. Drug resistance and mutation of the malaria parasite have presented significant hurdles in decreasing the persistently high mortality rates of malaria in children, particularly in highly endemic regions. Such complex factors in disease transmission and treatment present particularly difficult challenges for the iCCM approach, which relies on lesstrained CHWs and related cadres who may have elementary skills and knowledge in malaria. They may not be able to manage more complex cases present to them.

Implementation of $\mathrm{iCCM}$ interventions has encountered various challenges. They have included shortages of drugs and supplies, poor quality of care, and lack of $\mathrm{CHW}$ incentives, training and supervision [8]. Such challenges continue to risk stalling positive outcomes obtained through iCCM interventions. In particular, they risk the establishment, scale-up and sustainability of iCCM interventions in reducing child mortality. In some settings, CHWs in iCCM programmes have been tasked with roles beyond what they are trained to do $[7,10]$. Lack of health workers has influenced task-shifting from qualified medical personnel to $\mathrm{CHWs}$ for malaria case management as the only alternative. In other areas, where CHWs are the only personnel available, they have been used to deliver effective life-saving interventions [4].
Success of iCCM using CHWs and related cadres has been well documented. However, evidence of challenges and differing roles of CHWs and other lay health workers in various endemic regions has not been systematically examined. Challenges learnt from such varied implementation locations may help the process of adaptation of iCCM interventions in areas with similar characteristics. This systematic review was conducted to examine and summarize evidence on different roles of $\mathrm{CHWs}$ and related cadres in malaria prevention, case management and health promotion in malaria-endemic regions. This review also aimed to examine the challenges encountered by such health cadres in the implementation of iCCM.

\section{Methods}

This systematic review aimed to address two Population Intervention Comparator Outcome (PICO) questions: What is the role of CHWs and related cadres in malaria prevention, case management and health promotion in highly malaria-endemic regions? and, What are the challenges encountered while implementing iCCM for malaria using $\mathrm{CHWs}$ and related cadres?

In this review, the population of interest included $\mathrm{CHWs}$ and related cadres, such as village health volunteers and other lay health workers: home care providers and community medicine distributors. Qualified health cadres or those who had more formal and qualified training were excluded from this study. This also included mid-level providers and other official health workers employed to provide care in health facilities. Interventions of interest included $\mathrm{iCCM}$, community case management of malaria (CCMm), seasonal malaria chemoprevention (SMC), and home-based management of fever. This review did not include a comparison group because of the nature of the two PICO questions.

The outcome of interest for this review was the roles and challenges faced by $\mathrm{CHWs}$ and related cadres. Challenges of CHWs and the related cadres were defined in line with the health system building blocks put forth by WHO [11]. They were grouped into financing, workforce, medical products, information and research, service delivery, and stewardship.

The developed protocol was registered in the PROSPERO database for systematic reviews (Registration number CRD42015027878). The current review is set to answer two of the four research objectives in the registered protocol. These are examining roles and challenges encountered by $\mathrm{CHWs}$ working in malaria interventions in malaria-endemic regions. Evidence search was conducted in PubMed, CINAHL, ISI Web of Knowledge, and WHO regional databases. A Boolean phrase was prepared and used for evidence search in PubMed, while search terms were used in other databases. Studies with 
the following designs were included: randomized control trial; quasi-experimental; pre-post interventional; longitudinal and cohort; cross-sectional; case study; and, secondary data analysis. Evidence in form of opinion papers, reviews, editorials, and reports was excluded in this review.

A total of 1394 articles were retrieved. Of them, 617 articles were identified from PubMed and 777 articles from all other databases (Fig. 1). A total of 1380 were screened after removal of 14 articles as duplicates. Of the remaining, 1245 articles were further excluded based on their titles and abstracts. Only 139 articles were eligible for full text assessment based on inclusion and exclusion criteria. On the full text assessment, a total of 72 articles were further excluded based on differences in objectives $(\mathrm{n}=33)$, study design $(\mathrm{n}=15)$, participants $(\mathrm{n}=2)$, interventions $(n=6)$, outcomes $(n=5)$, and lack of the defined intervention $(n=11)$. Finally, a total of 68 articles were eligible for analysis. Excel spreadsheet was used to report the extracted data. Only a narrative synthesis on the included studies was conducted because of the differences in study designs and measurements of outcome variables.

\section{Results \\ Description of the selected studies}

This review retrieved studies conducted in regions with high malaria endemicity (Table 1). These included Southeast Asia and sub-Saharan Africa regions. In the retrieved studies, CHWs were the commonest health cadre in 38 studies. Others included community health volunteers, village malaria workers, community medicine distributors, village health workers, home care providers, accredited social health activists, volunteer community-directed

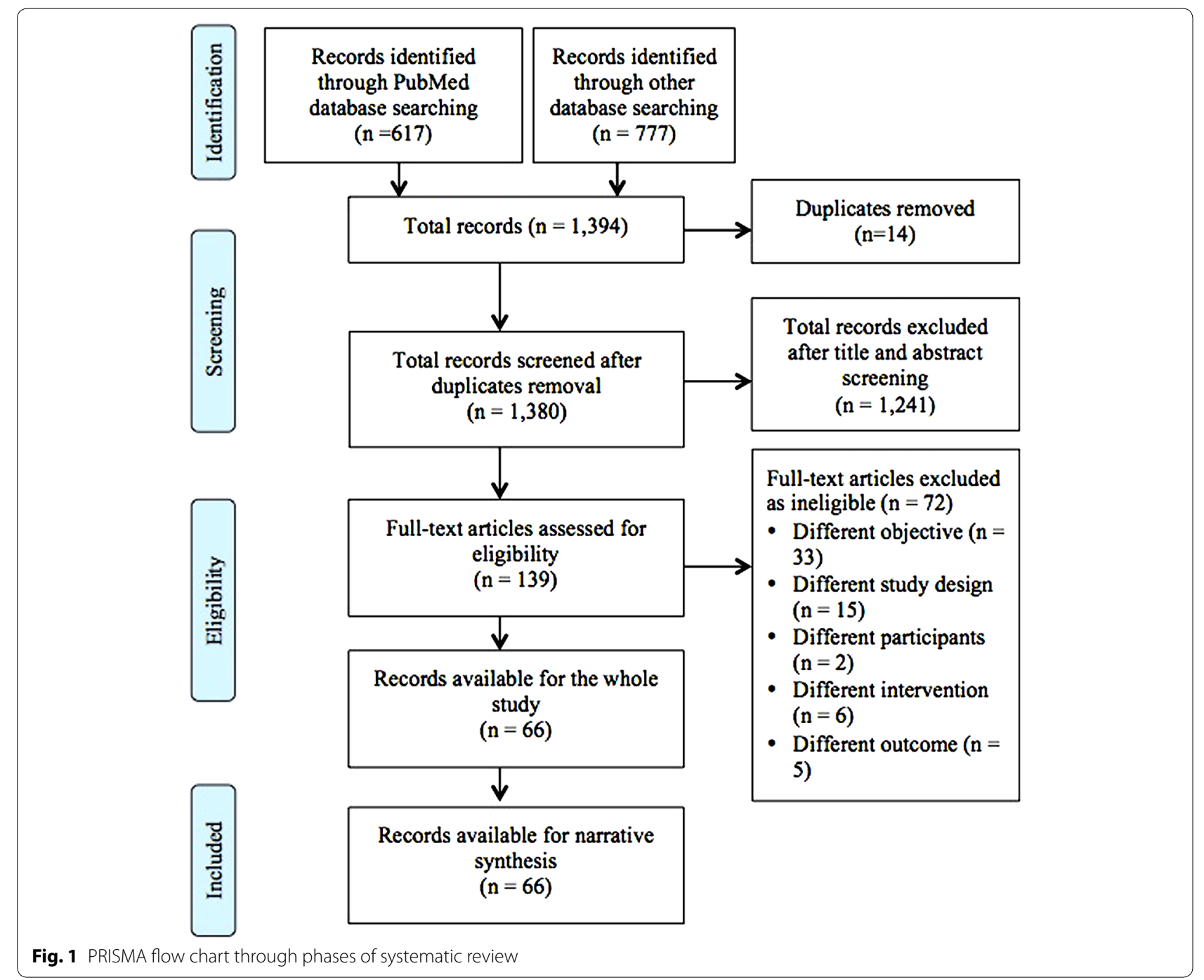




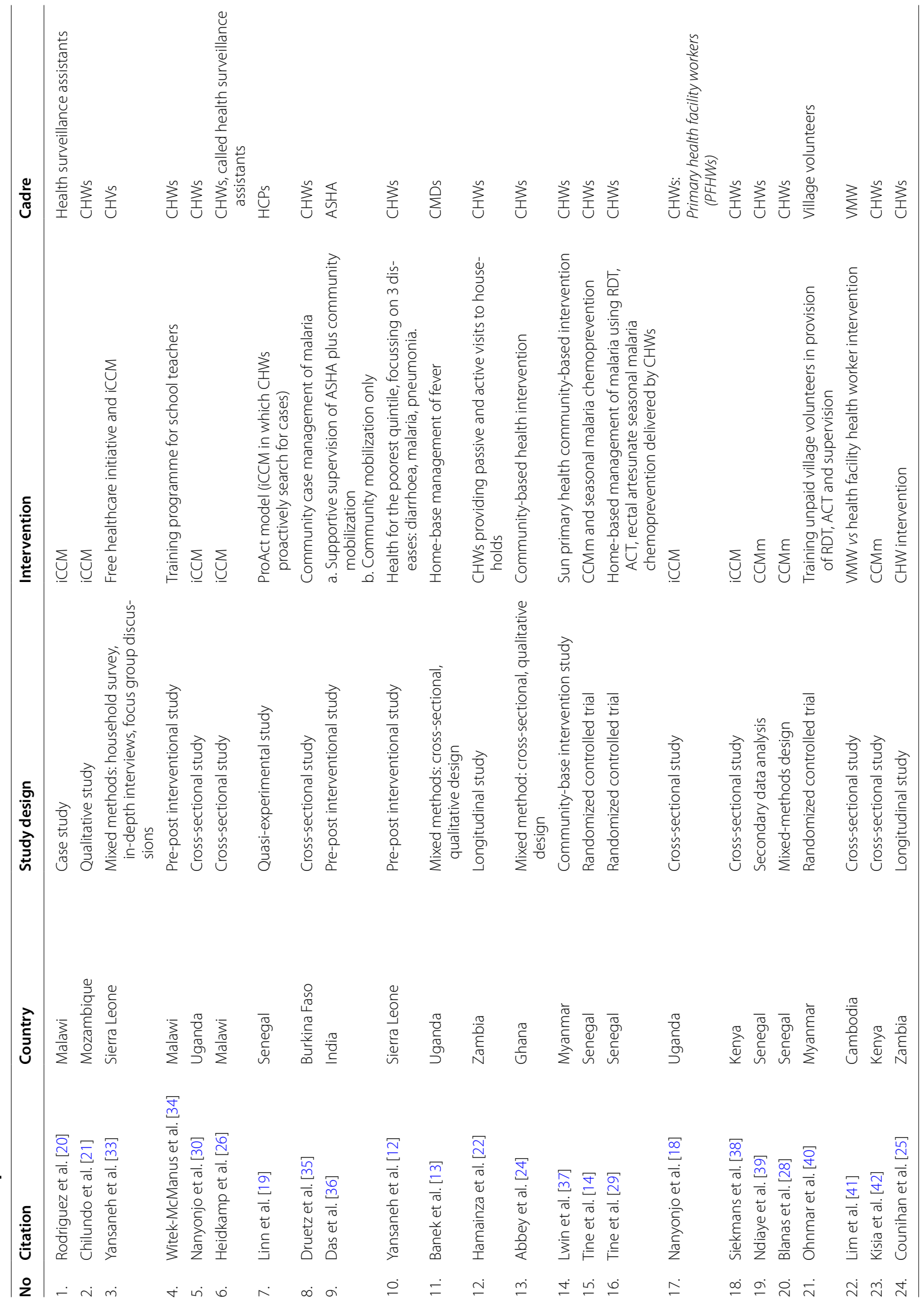




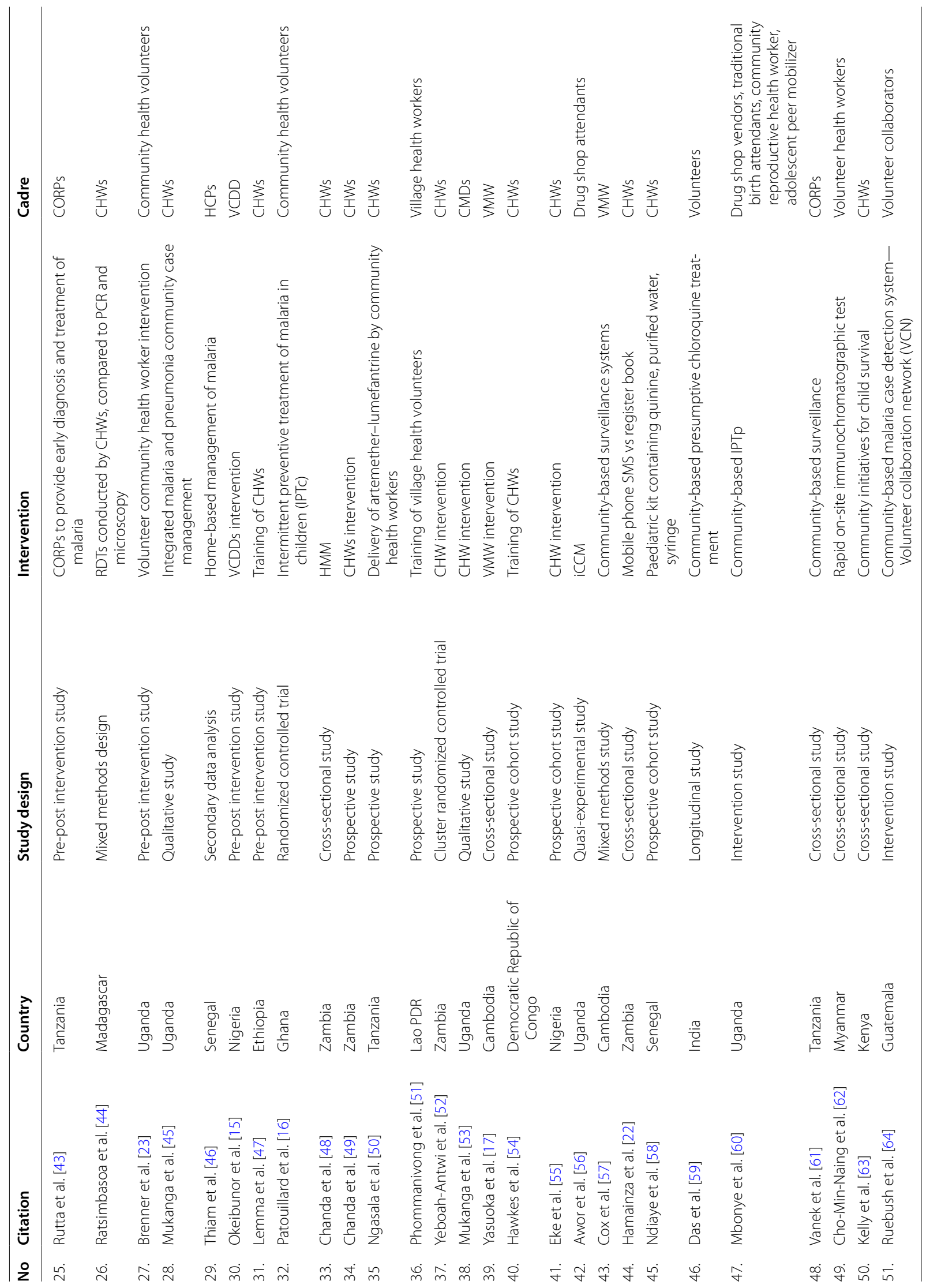




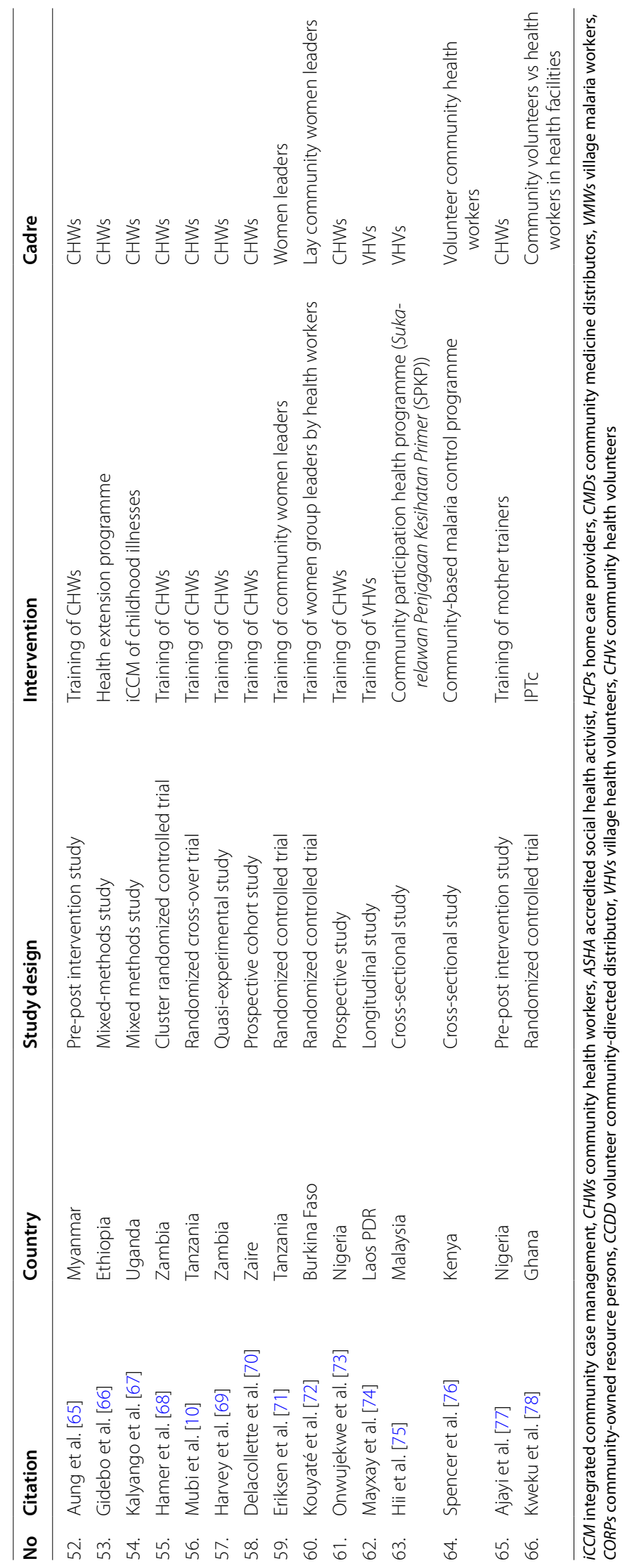


distributors, health surveillance assistants, village volunteers, community-owned resource persons, drug shop attendants, drug shop vendors, traditional birth attendants, community reproductive health workers, adolescent peer mobilizers, volunteer health workers, volunteer collaborators, women leaders, and mothers. In sub-Saharan Africa, the commonest cadre was $\mathrm{CHW}$, while in Asia it was village malaria worker.

\section{Role of CHWs and related cadres in malaria interventions}

Table 2 shows the different roles of CHWs and related cadres on malaria interventions. This review classified their roles into three main categories: malaria case management, prevention including health surveillance and health promotion specific to malaria. Such roles were reported in a total of 40 articles.

In malaria case management, $\mathrm{CHWs}$ and related cadres were involved in the diagnosis of malaria using rapid diagnostic tests (RDT). They were also involved in management of fever and the treatment of malaria using artemisinin combination therapy (ACT). In some studies, $\mathrm{CHWs}$ and related cadres were involved in prescription of anti-malarial drugs, delivery of anti-malarial drugs for home-based care and treatment or referral of complicated cases to the health facilities. In some cases they were the vital person in the community to accompany community members to seek care [12], or to provide home-based visitations for follow-up [13, 14] (Table 2).

Community health workers and related cadres were also involved in malaria preventive roles as shown in a few selected studies. Such roles included provision of intermittent preventive treatment for pregnant women (IPTp) [15] and for children (IPTc) [16]. CHWs and related cadres were also involved in distribution of insecticide-treated bed nets as one of the malaria prevention strategies [15].

The reviewed evidence also suggested that CHWs and the related cadres took part in a number of health promotion activities for malaria in various contexts $[14,15$, 17-19]. Examples of such roles included counselling for malaria prevention, early treatment and improving health-seeking behaviour. They provided health education about malaria and related complications, prevention and treatment.

\section{Challenges of CHWs and related cadres in malaria interventions}

Table 3 enumerates challenges and barriers CHWs and related cadres faced while implementing iCCM interventions. CHWs and related cadres faced health care financing challenges while implementing their roles in malaria interventions. This primarily included lack of sustainable sources of funds [20,21]. As a result, CHWs and related cadres often suffered from poor or no remuneration [12, 22 ] and lack of incentives. Because the majority work on a voluntary basis, there has been no accountability when they are absent from the workplace [23].

Community health workers and related cadres have been facing similar health workforce challenges to other cadres working in malaria-related interventions. There has been a widespread lack of in-service training and other forms of continuous professional development [20]. Other related challenges include high turnover due to high attrition rates, especially for those working in hardto-reach or remote areas [24], lack of incentives [23] and lack of motivation to continue with their work [12, 21].

Stewardship challenges also affected the role of CHWs and related cadres in malaria interventions. For example, in Malawi, abbreviated CHW training did not meet medical regulation standards for prescription resulting in CHWs not being allowed to prescribe anti-malarials [20]. Lack of supervision from qualified health workers and poor coordination from the existing health infrastructure affected implementation of CHWs' role in iCCM [20, 21, $25,26]$.

Lack of necessary medical supplies and medicine affected CHWs role in iCCM. Most studies mentioned stock-outs of ACT and other anti-malarials [21, 26, 27], test kits for malaria [13, 14, 25, 28] and gloves, among others [29].

Service delivery by CHWs working in malaria was impaired by a number of factors. First, CHWs and related cadres were not trusted to have adequate knowledge to care and treat malaria cases in some communities [21, 22 ,27]. As a result, people who had symptoms of malaria still had to travel long distances to seek similar care in health facilities [27]. Second, distances from where they were stationed to households in need affected their service delivery [13], and the referral of their patients [30]. Third, lack of transport and poor roads caused delays in service delivery in some studies [13,28].

Some of the iCCM and roles of CHWs and related cadres have not been evaluated [21]. This poses a challenge in scaling up this intervention to wider areas. Information and research are needed for understanding the challenges, lessons and areas for improvement when scaling up.

\section{Discussion}

The current study is the first systematic review that summarizes evidence on the roles and challenges of CHWs and related cadres working on malaria interventions. In this review, CHWs and related cadres were already tasked with different roles in malaria interventions. They included prevention, malaria case management and health promotion related to malaria. 
Table 2 Roles of CHWs, VMWs and lay personnel working on malaria

\begin{tabular}{|c|c|c|c|}
\hline SN & Citation & Cadre & Roles \\
\hline 1. & Rodriguez et al. [20] & Health surveillance assistants & $\begin{array}{l}\text { Treatment with ACT } \\
\text { Disease surveillance } \\
\text { Health promotion }\end{array}$ \\
\hline 2. & Chilundo et al. [21] & $\begin{array}{l}\text { CHWs: } \\
\text { Agentes Polivalentes Elementares (APEs) }\end{array}$ & $\begin{array}{l}\text { Prescription of anti-malarial } \\
\text { Management of malaria cases }\end{array}$ \\
\hline 3. & Yansaneh et al. [33] & Community health volunteers & $\begin{array}{l}\text { Malaria treatment } \\
\text { Health promotion } \\
\text { Referral of critical patients or those with danger signs } \\
\text { Accompanies malaria-sick patients to health facilities }\end{array}$ \\
\hline 4. & Witek-McManus et al. [34] & CHWs & $\begin{array}{l}\text { Diagnosis using RDT } \\
\text { Treatment using ACT }\end{array}$ \\
\hline 5. & Nanyonjo et al. [30] & CHWs & $\begin{array}{l}\text { Diagnosis } \\
\text { Patients' referral }\end{array}$ \\
\hline 6. & Linn et al. [19] & HCPs & Home visitation and health promotion \\
\hline 7. & Druetz et al. [35] & $\mathrm{CHWs}$ & $\begin{array}{l}\text { Patients consultations } \\
\text { Prescription and treatment }\end{array}$ \\
\hline 8. & Das et al. [36] & ASHA & $\begin{array}{l}\text { Patients consultations } \\
\text { Prescription and treatment }\end{array}$ \\
\hline 9. & Yansaneh et al. [12] & Community health volunteers & $\begin{array}{l}\text { Malaria treatment } \\
\text { Disease prevention }\end{array}$ \\
\hline 10. & Banek et al. [13] & (CMDs) & Home-based treatment of malaria \\
\hline 11. & Hamainza et al. [22] & CHWs & $\begin{array}{l}\text { Malaria treatment } \\
\text { Diagnosis using RDT }\end{array}$ \\
\hline 12. & Abbey et al. [24] & CHWs & Health promotion \\
\hline 13. & Tine et al. [14] & CHWs & $\begin{array}{l}\text { Malaria treatment } \\
\text { Health promotion }\end{array}$ \\
\hline 14. & Tine et al. [29] & CHWs & Home-based treatment and diagnosis \\
\hline 15. & Nanyonjo et al. [18] & Primary health facility workers (PFHWs) & $\begin{array}{l}\text { Facility treatment } \\
\text { Health promotion and prevention }\end{array}$ \\
\hline 16. & Siekmans et al. [38] & CHWs & Home-based treatment and diagnosis \\
\hline 17. & Ndiaye et al. [39] & $\mathrm{CHWS}$ & $\begin{array}{l}\text { Consultations } \\
\text { Treatment using ACT } \\
\text { Patients' referrals } \\
\text { Diagnosis using RDT }\end{array}$ \\
\hline 18. & Blanas et al. [28] & $\mathrm{CHWs}$ & $\begin{array}{l}\text { Treatment and prescription of ACT } \\
\text { Diagnosis with RDT } \\
\text { Selling anti-malarials at government prices }\end{array}$ \\
\hline 19. & Ohnmar et al. [40] & Village volunteers & $\begin{array}{l}\text { Treatment and prescription of ACT } \\
\text { Diagnosis with RDT }\end{array}$ \\
\hline 20. & Lim et al. [41] & Village malaria workers & Diagnosis \\
\hline 21. & Kisia et al. [42] & CHWs & Treatment and prescription of ACT \\
\hline 22. & Counihan et al. [25] & CHWs & Diagnosis using RDT \\
\hline 23. & Rutta et al. [43] & CORPS & $\begin{array}{l}\text { Diagnosis using RDT } \\
\text { Treatment using ACT } \\
\text { Referral of malaria cases }\end{array}$ \\
\hline 24. & Ratsimbasoa et al. [44] & $\mathrm{CHWs}$ & Diagnosis using RDT \\
\hline 25. & Brenner et al. [23] & Community health volunteers & $\begin{array}{l}\text { Diagnosis using RDT } \\
\text { Treatment using ACT }\end{array}$ \\
\hline 26. & Mukanga et al. [45] & $\mathrm{CHWs}$ & $\begin{array}{l}\text { Patients' consultation: taking history } \\
\text { Diagnosis with RDT } \\
\text { Patient's classification }\end{array}$ \\
\hline 27. & Thiam et al. [46] & HCPS & $\begin{array}{l}\text { Patients' consultation: taking history } \\
\text { Diagnosis with RDT } \\
\text { Treatment }\end{array}$ \\
\hline 28. & Okeibunor et al. [15] & CDDs & $\begin{array}{l}\text { Distribution of ITNs } \\
\text { Provision of IPTp drugs } \\
\text { Counselling services on prevention among pregnant women }\end{array}$ \\
\hline
\end{tabular}


Table 2 continued

\begin{tabular}{|c|c|c|c|}
\hline SN & Citation & Cadre & Roles \\
\hline 29. & Lemma et al. [47] & CHWs & $\begin{array}{l}\text { Diagnosis using RDT } \\
\text { Treatment of malaria }\end{array}$ \\
\hline 30. & Patouillard et al. [16] & Community health volunteers & Intermittent preventive treatment in children (IPTC) \\
\hline 31. & Chanda et al. [48] & CHWs & Diagnosis \\
\hline 32. & Chanda et al. [49] & CHWs & Treatment using anti-malarials \\
\hline 33. & Ngasala et al. [50] & $\mathrm{CHWs}$ & Treatment using anti-malarials (ACT) \\
\hline 34. & Phommanivong et al. [51] & Village health workers & $\begin{array}{l}\text { Diagnosis using RDT } \\
\text { Treatment of malaria }\end{array}$ \\
\hline 35. & Yeboah-Antwi et al. [52] & CHWs & $\begin{array}{l}\text { Diagnosis using RDT } \\
\text { Treatment using ACT }\end{array}$ \\
\hline 36. & Mukanga et al. [53] & CMDs & Diagnosis using RDT \\
\hline 37. & Yasuoka et al. [17] & Village malaria workers & $\begin{array}{l}\text { Diagnosis with RDTs } \\
\text { Prescribing anti-malarials } \\
\text { Active detection } \\
\text { Explanations about compliance } \\
\text { Follow-up of patients }\end{array}$ \\
\hline 38. & Hawkes et al. [54] & CHWs & $\begin{array}{l}\text { Diagnosis using RDT } \\
\text { Treatment of febrile conditions/malaria }\end{array}$ \\
\hline 39. & Eke et al. [55] & CHWs & Diagnosis using RDT \\
\hline 40. & Tipke et al. & Volunteer community health workers & Treatment using modern medicine \\
\hline 41. & Awor et al. [56] & Drug shop attendants & $\begin{array}{l}\text { Malaria testing with RTD } \\
\text { Malaria treatment with ACT }\end{array}$ \\
\hline 42. & Cox et al. [57] & Village malaria workers & Surveillance of day 3-positive Plasmodium falciparum cases \\
\hline 43. & Hamainza et al. [22] & CHWs & Diagnosis using RDT \\
\hline 44. & Ndiaye et al. [58] & CHWs & Use of paediatric kit containing quinine, purified water, syringe \\
\hline 45. & Das et al. [59] & Volunteers & Cases of fever treated during the 3-year period \\
\hline 46. & Mbonye et al. [60] & $\begin{array}{l}\text { Drug shop vendors, traditional birth attendants, community } \\
\text { reproductive health worker, adolescent peer mobilizer }\end{array}$ & Delivery of SP doses to pregnant women \\
\hline 47. & Vanek et al. [61] & CORPs & Number of malaria vector larval habitats \\
\hline 48. & Cho-Min-Naing et al. [62] & Volunteer health workers & Sensitivities of malaria parasites tests \\
\hline 49. & Kelly et al. [63] & CHWs & Treatment \\
\hline 50. & Ruebush et al. [64] & Volunteer collaborators & Number of patients treated \\
\hline 51. & Aung et al. [65] & CHWs & Diagnosis and treatment of paediatric malaria \\
\hline 52. & Gidebo et al. [66] & CHWs & Diagnosis and treatment \\
\hline 53. & Kalyango et al. [67] & CHWs & Treatment \\
\hline 54. & Hamer et al. [68] & CHWs & Use of RDT \\
\hline 55. & Mubi et al. [10] & CHWs & Provision of ACT \\
\hline 56. & Harvey et al. [69] & CHWs & Use of RDT \\
\hline 57. & Delacollette et al. [70] & CHWs & Treatment \\
\hline 58. & Phommanivong et al. [51] & Village health volunteers & $\begin{array}{l}\text { Use of RDT } \\
\text { Provision of ACT }\end{array}$ \\
\hline 59. & Eriksen et al. [71] & Women leaders & $\begin{array}{l}\text { Role of women leaders in recognizing symptoms and provid- } \\
\text { ing first-line treatment for uncomplicated malaria }\end{array}$ \\
\hline 60. & Kouyaté et al. [72] & Lay community women leaders & Malaria case management \\
\hline 61. & Onwujekwe et al. [73] & CHWs & Malaria treatment \\
\hline 62. & Mayxay et al. [74] & Village health volunteers & Use of RDT \\
\hline 63. & Hii et al. [75] & Village health volunteers & Treatment \\
\hline 64. & Spencer et al. [76] & Volunteer community health workers & Treatment with chloroquine \\
\hline 65. & Ajayi et al. [77] & CHWs & $\begin{array}{l}\text { Health promotion } \\
\text { Treatment of malaria }\end{array}$ \\
\hline 66. & Kweku et al. [78] & Community volunteers vs health workers in health facilities & Administration of amodiaquine plus SP \\
\hline
\end{tabular}

CHWs community health workers, ASHA accredited social health activist, HCPs home care providers, CMDs community medicine distributors, VMWs village malaria workers, CORPs community-owned resource persons, CCDD volunteer community-directed distributor, VHVs village health volunteers 
Table 3 Challenges of CHWs, VMWs and lay personnel working on malaria

\begin{tabular}{|c|c|c|c|}
\hline SN & Citation & Cadre & Challenges \\
\hline 1. & Rodriguez et al. [20] & $\begin{array}{l}\text { Health surveillance assis- } \\
\text { tants }\end{array}$ & $\begin{array}{l}\text { Short training not in-keeping with medical regulation standards for prescription } \\
\text { Lack of resources to lengthen training } \\
\text { Poor supervision and overburden with patients } \\
\text { Most are found in remote and hard-to-reach areas where frequent supervision is not routine } \\
\text { Job description keeps changing with more introduction of community interventions } \\
\text { Financial instability and poor sustainability because of donor dependence and other unreli- } \\
\text { able sources }\end{array}$ \\
\hline 2. & Chilundo et al. [21] & CHWs & $\begin{array}{l}\text { Policy conflicts on prescription. Authority does not allow personnel with short-term training } \\
\text { to prescribe } \\
\text { Stock out of supplies especially anti-malarials } \\
\text { Poor supervision especially in the hard to reach areas } \\
\text { Funding instability. The programme is donor funded and subjected to delays in funding } \\
\text { disbursement } \\
\text { Lack of community involvement and ownership } \\
\text { No evidence yet on impact and no evaluation strategy } \\
\text { APEs are not paid }\end{array}$ \\
\hline 3. & Yansaneh et al. [33] & $\mathrm{CHVs}$ & $\begin{array}{l}\text { CHVs are not remunerated and have to do other income generating activities } \\
\text { Not available when needed as they are not paid for their service }\end{array}$ \\
\hline 4. & Nanyonjo et al. [30] & CHWs & Patients may not complete referrals \\
\hline 5. & Heidkamp et al. [26] & CHWs & $\begin{array}{l}\text { Stock-out of essential supplies } \\
\text { Poor supervision from higher cadres }\end{array}$ \\
\hline 6. & Druetz et al. [35] & CHWs & $\begin{array}{l}\text { Community preference on qualified health workers } \\
\text { CHWs not known to people } \\
\text { Medicine stock-out } \\
\text { Long distance to CHWs }\end{array}$ \\
\hline 7. & Banek et al. [13] & CMDs & $\begin{array}{l}\text { Patients overload } \\
\text { Lack of supervision } \\
\text { Limited malaria knowledge } \\
\text { Tensions with community members } \\
\text { Lack of remuneration from the government }\end{array}$ \\
\hline 8. & Hamainza et al. [22] & CHWs & $\begin{array}{l}\text { Lack of remuneration } \\
\text { Negative attitudes to care given by CHWs } \\
\text { Weak social responsibilities }\end{array}$ \\
\hline 9. & Abbey et al. [24] & CHWs & High attrition rate of CHWs especially in hard-to-reach areas \\
\hline 10. & Tine et al. [14] & CHWs & Medicine and RDT stock-out \\
\hline 11. & Ndiaye et al. [39] & CHWs & Medicine and supply RDT stock-out (ACT, RDT, gloves, case files, patients forms) \\
\hline 12. & Blanas et al. [28] & CHWs & $\begin{array}{l}\text { ACT and other supplies stock-outs } \\
\text { Expired medicines or unavailable in villages } \\
\text { Scepticism from villages } \\
\text { Transport problems, poor infrastructure and long distances for referrals }\end{array}$ \\
\hline 13. & Counihan et al. [25] & CHWs & $\begin{array}{l}\text { RDT and other medical supply stock-outs after initial supplies finished } \\
\text { Lack of supervision } \\
\text { Sustainability }\end{array}$ \\
\hline 14. & Brenner et al. [23] & $\mathrm{CHVs}$ & $\begin{array}{l}\text { Low turn-over of CHVs } \\
\text { Low motivation } \\
\text { Inconsistent supplies of medicine and supplies }\end{array}$ \\
\hline 15. & Gidebo et al. [66] & CHWs & $\begin{array}{l}\text { Shortage of chloroquine, } \\
\text { Patient pressure to take coartem }\end{array}$ \\
\hline 16. & $\begin{array}{l}\text { Delacollette et al. } \\
\text { [70] }\end{array}$ & CHWs & $\begin{array}{l}\text { CHWs' position remains ambiguous in the healthcare system. } \\
\text { Non-comprehensive care may have negative effect on the sustainability of programme }\end{array}$ \\
\hline 17. & Ajayi et al. [77] & CHWs & $\begin{array}{l}\text { Challenges in their promotion/training activities } \\
\text { The community members were not in support of the project. } \\
\text { Some community members felt trainers were wasting their time } \\
\text { Trainers could not conduct training all the time because of their domestic needs }\end{array}$ \\
\hline
\end{tabular}


Community health workers and related cadres constitute the majority of potential health workforce for malaria and many other health-related interventions. Within the realm of malaria, understanding the breadth of their potential roles is an essential first step in order to best utilize the abundant pool of CHWs and related cadres. Their importance is augmented in the setting of human resource health crises, an overwhelming problem in most malaria-burdened countries due to their low-income country status [31]. The potential of utilizing CHWs and related cadres brings new hope in addressing both malaria and human resources for health challenges in such countries. This alternative resource can fill the gap if carefully tailored to suit the context [6] in order that efforts to control malaria and reduce morbidity and mortality can be achieved [7, 27].

Evidence presented shows a number of health system challenges [11] that CHWs and related cadres face. Such challenges have also been experienced in different settings with implementation of malaria interventions using other qualified cadres. The financial challenge is lack of stable funding to implement iCCM. In most settings of high malaria endemicity, malaria projects have been operating in donor-driven programmes that run vertically and were not integrated into the existing health system to ensure efficacy, timely delivery and to cut down bureaucracy. They have been expensive to run and lack sustainability beyond a project's duration [32]. To ensure sustainability, CHWs and related cadres should be integrated into the health system infrastructure.

Short-term and focused training for CHWs and related cadres is a strength of iCCM. However, its cost effectiveness is a challenge in the implementation of malaria intervention, in particular, medical prescription and treatment [21]. It conflicts with other policies and regulations that require prescribers to have a minimum of training which is longer than that given to CHWs for iCCM [20, 32]. Short-term training reduces the community's confidence in CHWs and related health cadres, which affects their utilization [22]. Tailor-made curricula for CHWs and related cadres should address conflicting policies and involve key stakeholders to ameliorate lack of confidence by the community.

Health workforce challenges are common among CHWs and related cadres. They include low or no remuneration, lack of recognition from some of the public health system, lack of incentives, and poor transport to remote areas. These are not uncommon causes of attrition, even among qualified medical and other health cadres. Addressing such challenges will help to deploy and retain CHWs and related cadres in hard-to-reach areas and solve the health workforce crisis in malaria-endemic areas.
Ensuring constant supply of anti-malarial and diagnostic tools, such as RDT and other supplies, is vital to implementation of iCCM. This review found that stockouts were a common challenge. In some studies, the first consignment given after training of CHWs was never replaced when it ran out. To ensure reliable supply, health systems should incorporate CHWs and related cadres in malaria interventions as part of its strategy.

The evidence presented should be interpreted carefully owing to the following two limitations. First, meta-analysis could not be conducted on the retrieved evidence owing to differences in study designs and differences in outcome measures. However, the narrative synthesis was more suitable to this study to take advantage of different experiences and challenges encountered. Second, all lay health workers were included and combined together. Such health workers' levels of knowledge, training duration, and context differed from one region to another. However, evidence generated has consistently shown similar roles and challenges of these cadres in malaria interventions.

\section{Conclusions}

Community health workers and related cadres have been taking roles similar to those of more qualified health workers. They are important actors in malaria control and elimination but suffer from the health system challenges including financing, logistics, human resource management, and stewardship. To meet targets in sustainable development in health and to save countless lives and morbidity, CHWs and related cadres must be well resourced and sustained.

\section{Authors' contributions}

BFS conceived the research questions, prepare and registered the review protocol, conducted the literature search, analysed the data, and prepared the first draft of the manuscript. LBM conducted the literature search, analysed the data, and prepared the first draft of the manuscript. RA conducted the literature search, and analysed the data. MJ conceived the research questions, supervised the research team on protocol development and registration, analyses and manuscript preparation. All authors read and approved the final manuscript.

\section{Author details \\ ${ }^{1}$ Department of Community Health, School of Public Health and Social Sciences, Muhimbili University of Health and Allied Sciences, Dar es Salaam, Tanzania. ${ }^{2}$ Management for Development and Health, Dar es Salaam, Tanza- nia. ${ }^{3}$ Department of Community and Global Health, The University of Tokyo, Tokyo, Japan.}

\section{Competing interests}

The authors declare that they have no competing interests.

Availability of data and materials

All the articles used for the analyses are listed in Tables 1 and 2.

\section{Ethics approval and consent to participate}

Efforts was made to ensure that all included articled adhered to the ethical standards and obtained ethical approval beforehand. 


\section{Funding}

Authors did not receive any grant for this systematic review.

Received: 8 October 2016 Accepted: 22 December 2016 Published online: 03 January 2017

\section{References}

1. Global Burden of Disease Collaborators. Global, regional, and national age-sex specific all-cause and cause-specific mortality for 240 causes of death, 1990-2013: a systematic analysis for the global burden of disease study. Lancet. 2013:2015(385):117-71.

2. Bhutta ZA, Das JK, Rizvi A, Gaffey MF, Walker N, Horton S, et al. Evidencebased interventions for improvement of maternal and child nutrition: what can be done and at what cost? Lancet. 2013;382:452-77.

3. Bhutta ZA, Ahmed T, Black RE, Cousens S, Dewey K, Giugliani E, et al. What works? Interventions for maternal and child undernutrition and survival. Lancet. 2008;371:417-40.

4. Bhutta ZA, Lassi ZS. Empowering communities for maternal and newborn health. Lancet. 2010;375:1142-4.

5. Lassi ZS, Haider BA, Bhutta ZA. Community-based intervention packages for reducing maternal and neonatal morbidity and mortality and improving neonatal outcomes. Cochrane Database Syst Rev. 2015;3:7754.

6. Christopher JB, Le May A, Lewin S, Ross DA. Thirty years after Alma-Ata: a systematic review of the impact of community health workers delivering curative interventions against malaria, pneumonia and diarrhoea on child mortality and morbidity in sub-Saharan Africa. Hum Resour Health. 2011;9:27.

7. WHO, GHWA: Global experience of community health workers for delivery of health related millennium development goals: a systematic review, country cases studies, and recommendation for integration into national health system. Geneva: World health Organization; 2010.

8. de Sousa A, Tiedje KE, Recht J, Bjelic I, Hamer DH. Community case management of childhood illnesses: policy and implementation in Countdown to 2015 countries. Bull World Health Organ. 2012;90:183-90.

9. Vaughan K, Kok MC, Witter S, Dieleman M. Costs and cost-effectiveness of community health workers: evidence from a literature review. Hum Resour Health. 2015;13:71.

10. Mubi M, Janson A, Warsame M, Mårtensson A, Källander K, Petzold MG, et al. Malaria rapid testing by community health workers is effective and safe for targeting malaria treatment: randomised cross-over trial in Tanzania. PLoS ONE. 2011;6:e19753.

11. WHO: Monitoring the building blocks of health systems: a handbook of indicators and their measurement strategies. Geneva: World Health Organization; 2010

12. Yansaneh Al, Moulton LH, George AS, Rao SR, Kennedy N, Bangura P, et al. Influence of community health volunteers on care seeking and treatment coverage for common childhood illnesses in the context of free health care in rural Sierra Leone. Trop Med Int Health. 2014;19:1466-76.

13. Banek K, Nankabirwa J, Maiteki-Sebuguzi C, DiLiberto D, Taaka L, Chandler $\mathrm{Cl}$, et al. Community case management of malaria: exploring support, capacity and motivation of community medicine distributors in Uganda. Health Policy Plan. 2015;30:451-61.

14. Tine RC, Ndiaye P, Ndour CT, Faye B, Ndiaye JL, Sylla KN, et al. Acceptability by community health workers in Senegal of combining community case management of malaria and seasonal malaria chemoprevention. Malar J. 2013;12:467.

15. Okeibunor JC, Orji BC, Brieger W, Ishola G, Otolorin E, Rawlins B, et al. Preventing malaria in pregnancy through community-directed interventions: evidence from Akwa Ibom State, Nigeria. Malar J. 2011;10:227.

16. Patouillard E, Conteh L, Webster J, Kweku M, Chandramohan D, Greenwood B. Coverage, adherence and costs of intermittent preventive treatment of malaria in children employing different delivery strategies in Jasikan, Ghana. PLoS ONE. 2011;6:e24871.

17. Yasuoka J, Poudel KC, Poudel-Tandukar K, Nguon C, Ly P, Socheat D, et al. Assessing the quality of service of village malaria workers to strengthen community-based malaria control in Cambodia. Malar J. 2010;9:109.

18. Nanyonjo A, Makumbi F, Etou P, Tomson G, Källander K. Perceived quality of care for common childhood illnesses: facility versus community based providers in Uganda. PLoS ONE. 2013;8:e79943.
19. Linn AM, Ndiaye Y, Hennessee I, Gaye S, Linn P, Nordstrom K, et al. Reduction in symptomatic malaria prevalence through proactive community treatment in rural Senegal. Trop Med Int Health. 2015;20:1438-46.

20. Rodríguez DC, Banda H, Namakhoma I. Integrated community case management in Malawi: an analysis of innovation and institutional characteristics for policy adoption. Health Policy Plan. 2015;30(Suppl 2):74-83.

21. Chilundo BG, Cliff JL, Mariano AR, Rodríguez DC, George A. Relaunch of the official community health worker programme in Mozambique: is there a sustainable basis for iCCM policy? Health Policy Plan. 2015;30(Suppl 2):54-64.

22. Hamainza B, Moonga $\mathrm{H}$, Sikaala $\mathrm{CH}$, Kamuliwo M, Bennett $\mathrm{A}$, Eisele TP, et al. Monitoring, characterization and control of chronic, symptomatic malaria infections in rural Zambia through monthly household visits by paid community health workers. Malar J. 2014;13:128.

23. Brenner JL, Kabakyenga J, Kyomuhangi T, Wotton KA, Pim C, Ntaro M, et al. Can volunteer community health workers decrease child morbidity and mortality in southwestern Uganda? An impact evaluation. PLOS ONE. 2011;6:e27997.

24. Abbey M, Bartholomew LK, Nonvignon J, Chinbuah MA, Pappoe M, Gyapong $\mathrm{M}$, et al. Factors related to retention of community health workers in a trial on community-based management of fever in children under 5 years in the Dangme West District of Ghana. Int Health. 2014;6:99-105.

25. Counihan $\mathrm{H}$, Harvey SA, Sekeseke-Chinyama M, Hamainza B, Banda R, Malambo T, et al. Community health workers use malaria rapid diagnostic tests (RDTs) safely and accurately: results of a longitudinal study in Zambia. Am J Trop Med Hyg. 2012;87:57-63.

26. Heidkamp R, Hazel E, Nsona H, Mleme T, Jamali A, Bryce J. Measuring implementation strength for integrated community case management in Malawi: results from a national cell phone census. Am J Trop Med Hyg. 2015;93:861-8.

27. Druetz T, Ridde V, Kouanda S, Ly A, Diabaté S, Haddad S. Utilization of community health workers for malaria treatment: results from a threeyear panel study in the districts of Kaya and Zorgho, Burkina Faso. Malar J. 2015;14:71.

28. Blanas DA, Ndiaye Y, Nichols K, Jensen A, Siddiqui A, Hennig N. Barriers to community case management of malaria in Saraya, Senegal: training, and supply-chains. Malar J. 2013;12:95

29. Tine RC, Ndour CT, Faye B, Cairns M, Sylla K, Ndiaye MN, et al. Feasibility, safety and effectiveness of combining home based malaria management and seasonal malaria chemoprevention in children less than 10 years in Senegal: a cluster-randomised trial. Trans R Soc Trop Med Hyg. 2014;108:13-21.

30. Nanyonjo A, Bagorogoza B, Kasteng F, Ayebale G, Makumbi F, Tomson G et al. Estimating the cost of referral and willingness to pay for referral to higher-level health facilities: a case series study from an integrated community case management programme in Uganda. BMC Health Serv Res. 2015;15:347.

31. WHO: The World Health Report. Working together for health. Geneva: World Health Organization; 2006.

32. Rodríguez DC, Shearer J, Mariano AR, Juma PA, Dalglish SL, Bennett S. Evidence-informed policymaking in practice: country-level examples of use of evidence for iCCM policy. Health Policy Plan. 2015;30(Suppl 2):36-45.

33. Yansaneh Al, George AS, Sharkey A, Brieger WR, Moulton LH, Yumkella $\mathrm{F}$, et al. Determinants of utilization and community experiences with community health volunteers for treatment of childhood illnesses in rural Sierra Leone. J Community Health. 2015;41:376-86.

34. Witek-McManus S, Mathanga DP, Verney A, Mtali A, Ali D, Sande J, et al. Design, implementation and evaluation of a training programme for school teachers in the use of malaria rapid diagnostic tests as part of a basic first aid kit in southern Malawi. BMC Public Health. 2015:15:904.

35. Druetz T, Fregonese F, Bado A, Millogo T, Kouanda S, Diabaté S, Haddad S. Abolishing fees at health centers in the context of community case management of malaria: what effects on treatmentseeking practices for febrile children in rural Burkina Faso? PLoS ONE. 2015;10:e0141306.

36. Das A, Friedman J, Kandpal E, Ramana GN, Gupta RK, Pradhan MM, et al. Strengthening malaria service delivery through supportive supervision and community mobilization in an endemic Indian setting: an evaluation of nested delivery models. Malar J. 2014;13:482. 
37. Lwin MM, Sudhinaraset M, San AK, Aung T. Improving malaria knowledge and practices in rural Myanmar through a village health worker intervention: a cross-sectional study. Malar J. 2014;13:5

38. Siekmans K, Sohani S, Kisia J, Kiilu K, Wamalwa E, Nelima F, et al. Community case management of malaria: a pro-poor intervention in rural Kenya. Int Health. 2013;5:196-204.

39. Ndiaye D, Ndiaye M, Gueye PA, Badiane A, Fall ID, Ndiaye YD, et al. Intestinal helminthiasis diagnosed in Dakar, Senegal. Med Sante Trop. 2013;23:35-8.

40. Ohnmar Tun-Min, San-Shwe Than-Win, Chongsuvivatwong V. Effects of malaria volunteer training on coverage and timeliness of diagnosis: a cluster randomized controlled trial in Myanmar. Malar J. 2012;11:309.

41. Lim S, Yasuoka J, Poudel KC, Ly P, Nguon C, Jimba M. Promoting community knowledge and action for malaria control in rural Cambodia: potential contributions of Village Malaria Workers. BMC Res Notes. 2012;5:405

42. Kisia J, Nelima F, Otieno DO, Kiilu K, Emmanuel W, Sohani S, et al. Factors associated with utilization of community health workers in improving access to malaria treatment among children in Kenya. Malar J. 2012;11:248.

43. Rutta AS, Francis F, Mmbando BP, Ishengoma DS, Sembuche SH, Malecela EK, et al. Using community-owned resource persons to provide early diagnosis and treatment and estimate malaria burden at community level in north-eastern Tanzania. Malar J. 2012;11:152.

44. Ratsimbasoa A, Ravony H, Vonimpaisomihanta JA, Raherinjafy R, Jahevitra $M$, Rapelanoro R, et al. Management of uncomplicated malaria in febrile under five-year-old children by community health workers in Madagascar: reliability of malaria rapid diagnostic tests. Malar J. 2012;11:85.

45. Mukanga D, Babirye R, Peterson S, Pariyo GW, Ojiambo G, Tibenderana JK, et al. Can lay community health workers be trained to use diagnostics to distinguish and treat malaria and pneumonia in children? Lessons from rural Uganda. Trop Med Int Health. 2011;16:1234-42.

46. Thiam S, Thwing J, Diallo I, Fall FB, Diouf MB, Perry R, et al. Scale-up of home-based management of malaria based on rapid diagnostic tests and artemisinin-based combination therapy in a resource-poor country: results in Senegal. Malar J. 2012;11:334.

47. Lemma H, Byass P, Desta A, Bosman A, Costanzo G, Toma L, et al. Deploying artemether-lumefantrine with rapid testing in Ethiopian communities: impact on malaria morbidity, mortality and healthcare resources. Trop Med Int Health. 2010;15:241-50.

48. Chanda P, Hamainza B, Moonga HB, Chalwe V, Pagnoni F. Community case management of malaria using ACT and RDT in two districts in Zambia: achieving high adherence to test results using community health workers. Malar J. 2011;10:158.

49. Chanda P, Hamainza B, Moonga HB, Chalwe V, Banda P, Pagnoni F. Relative costs and effectiveness of treating uncomplicated malaria in two rural districts in Zambia: implications for nationwide scale-up of home-based management. Malar J. 2011;10:159.

50. Ngasala BE, Malmberg M, Carlsson AM, Ferreira PE, Petzold MG, Blessborn $D$, et al. Effectiveness of artemether-lumefantrine provided by community health workers in under-five children with uncomplicated malaria in rural Tanzania: an open label prospective study. Malar J. 2011;10:64.

51. Phommanivong V, Thongkham K, Deyer G, Rene JP, Barennes H. An assessment of early diagnosis and treatment of malaria by village health volunteers in the Lao PDR. Malar J. 2010;9:347.

52. Yeboah-Antwi K, Pilingana P, Macleod WB, Semrau K, Siazeele K, Kalesha $P$, et al. Community case management of fever due to malaria and pneumonia in children under five in Zambia: a cluster randomized controlled trial. PLoS Med. 2010;7:e1000340.

53. Mukanga D, Tibenderana JK, Kiguli J, Pariyo GW, Waiswa P, Bajunirwe F, et al. Community acceptability of use of rapid diagnostic tests for malaria by community health workers in Uganda. Malar J. 2010;9:203.

54. Hawkes M, Katsuva JP, Masumbuko CK. Use and limitations of malaria rapid diagnostic testing by community health workers in war-torn Democratic Republic of Congo. Malar J. 2009;8:308.

55. Eke R, Ee E. Diagnosis of malaria by community health workers in Nigeria. East Afr J Public Health. 2009;6:15-6.

56. Awor P, Wamani H, Tylleskar T, Peterson S. Drug seller adherence to clinical protocols with integrated management of malaria, pneumonia and diarrhoea at drug shops in Uganda. Malar J. 2015;14:277.
57. Cox J, Sovannaroth S, Dy Soley L, Ngor P, Mellor S, Roca-Feltrer A. Novel approaches to risk stratification to support malaria elimination: an example from Cambodia. Malar J. 2014;13:371.

58. Ndiaye JL, Tine RC, Faye B, Dieye eH, Lameyre PA, Dieye V, et al. Pilot feasibility study of an emergency paediatric kit for intra-rectal quinine administration used by the personnel of community-based health care units in Senegal. Malar J. 2007;6:152.

59. Das LK, Jambulingam P, Sadanandane C. Impact of community-based presumptive chloroquine treatment of fever cases on malaria morbidity and mortality in a tribal area in Orissa State, India. Malar J. 2008;7:75.

60. Mbonye AK, Bygbjerg IC, Magnussen P. A community-based delivery system of intermittent preventive treatment of malaria in pregnancy and its effect on use of essential maternity care at health units in Uganda. Trans R Soc Trop Med Hyg. 2007;101:1088-95.

61. Vanek MJ, Shoo B, Mtasiwa D, Kiama M, Lindsay SW, Fillinger U, et al. Community-based surveillance of malaria vector larval habitats: a baseline study in urban Dar es Salaam, Tanzania. BMC Public Health. 2006;6:154.

62. Min-Naing C, Gatton ML. Performance appraisal of rapid on-site malaria diagnosis (ICT malaria Pf/Pv test) in relation to human resources at village level in Myanmar. Acta Trop. 2002;81:13-9.

63. Kelly JM, Osamba B, Garg RM, Hamel MJ, Lewis JJ, Rowe SY, et al. Community health worker performance in the management of multiple childhood illnesses: Siaya District, Kenya, 1997-2001. Am J Public Health. 2001;91:1617-24.

64. Ruebush TK, Zeissig R, Klein RE, Godoy HA. Community participation in malaria surveillance and treatment. II. Evaluation of the volunteer collaborator Network of Guatemala. Am J Trop Med Hyg. 1992;46:261-71.

65. Aung T, Longfield K, Aye NM, San AK, Sutton TS, Montagu D, et al. Improving the quality of paediatric malaria diagnosis and treatment by rural providers in Myanmar: an evaluation of a training and support intervention. Malar J. 2015;14:397.

66. Summoro TS, Gidebo KD, Kanche ZZ, Woticha EW. Evaluation of trends of drug-prescribing patterns based on WHO prescribing indicators at outpatient departments of four hospitals in southern Ethiopia. Drug Des Dev Ther. 2015;9:4551-7.

67. Kalyango JN, Rutebemberwa E, Alfven T, Ssali S, Peterson S, Karamagi C. Performance of community health workers under integrated community case management of childhood illnesses in eastern Uganda. Malar J. 2012;11:282.

68. Hamer DH, Brooks ET, Semrau K, Pilingana P, MacLeod WB, Siazeele K, et al. Quality and safety of integrated community case management of malaria using rapid diagnostic tests and pneumonia by community health workers. Pathog Glob Health. 2012;106:32-9.

69. Harvey SA, Jennings L, Chinyama M, Masaninga F, Mulholland K, Bell DR. Improving community health worker use of malaria rapid diagnostic tests in Zambia: package instructions, job aid and job aid-plus-training. Malar J. 2008;7:160.

70. Delacollette C, Van der Stuyft P, Molima K. Using community health workers for malaria control: experience in Zaire. Bull World Health Organ. 1996;74:423-30.

71. Eriksen J, Mujinja P, Warsame M, Nsimba S, Kouyaté B, Gustafsson LL, et al. Effectiveness of a community intervention on malaria in rural Tanzaniaa randomised controlled trial. Afr Health Sci. 2010;10:332-40.

72. Kouyaté B, Somé F, Jahn A, Coulibaly B, Eriksen J, Sauerborn R, et al. Process and effects of a community intervention on malaria in rural Burkina Faso: randomized controlled trial. Malar J. 2008;7:50.

73. Onwujekwe O, Dike N, Ojukwu J, Uzochukwu B, Ezumah N, Shu E, et al. Consumers stated and revealed preferences for community health workers and other strategies for the provision of timely and appropriate treatment of malaria in southeast Nigeria. Malar J. 2006;5:117.

74. Mayxay M, Newton PN, Yeung S, Pongvongsa T, Phompida S, Phetsouvanh $\mathrm{R}$, et al. An assessment of the use of malaria rapid tests by village health volunteers in rural Laos. Trop Med Int Health. 2004;9:325-9.

75. Hii JL, Chee KC, Vun YS, Awang J, Chin KH, Kan SK. Sustainability of a successful malaria surveillance and treatment program in a Runggus community in Sabah, east Malaysia. Southeast Asian J Trop Med Public Health. 1996:27:512-21.

76. Spencer HC, Kaseje DC, Mosley WH, Sempebwa EK, Huong AY, Roberts JM. Impact on mortality and fertility of a community-based malaria control programme in Saradidi, Kenya. Ann Trop Med Parasitol. 1987;81(Suppl 1):36-45. 
77. Ajayi IO, Browne EN, Garshong B, Bateganya F, Yusuf B, Agyei-Baffour $\mathrm{P}$, et al. Feasibility and acceptability of artemisinin-based combination therapy for the home management of malaria in four African sites. Malar J. 2008;7:6.
78. Kweku M, Webster J, Adjuik M, Abudey S, Greenwood B, Chandramohan D. Options for the delivery of intermittent preventive treatment for malaria to children: a community randomised trial. PLOS ONE. 2009:4:e7256.
Submit your next manuscript to BioMed Central and we will help you at every step:

- We accept pre-submission inquiries

- Our selector tool helps you to find the most relevant journal

- We provide round the clock customer support

- Convenient online submission

- Thorough peer review

- Inclusion in PubMed and all major indexing services

- Maximum visibility for your research

Submit your manuscript at www.biomedcentral.com/submit
() Biomed Central 